\title{
Research on the Conditions and Approaches for Developing MOOCs in Shanxi Universities
}

\author{
QIU Yuxia \\ School of Management Science and Engineering \\ Shanxi University of Finance and Economics, SXUFE \\ Taiyuan, China \\ tyqyxljl@sina.cn \\ ZHANG Qianyu* \\ School of Management Science and Engineering \\ Shanxi University of Finance and Economics, SXUFE \\ Taiyuan, China \\ 773562207@qq.com
}

\begin{abstract}
The emergence of MOOCs has broken the traditional classroom teaching model of higher education. A new Sharing Model of "teaching" and "learning" is coming. Faced with the storm of MOOCs, Chinese universities should take the initiative to take advantage of the situation and combine the advantages of MOOCs with our classroom teaching. This paper takes Shanxi colleges and universities as the focal point. The conditions for developing MOOCs in Shanxi universities are analyzed, such as government support, university policy, teacher resources and teaching resources. At last, a four-phase implementation path, including pre-preparation phase, the class discussion stage, after-school review stage and final assessment stage, is put forward. That could provide some reference for Shanxi education reform.
\end{abstract}

Keywords - the colleges and universities in Shanxi Province; MOOCs; Conditions and pathways

\section{INTRODUCTION}

MOOCs is the short for Massively Open Online Courses. It is essentially distance education. Its basic features include large-scale, open, online learning and online video. As a new form of curriculum and teaching mode resulting from the deep integration of Internet information technology and education, it is different from the traditional classroom teaching and the original online public video course.

Since 2008 when the concept of MOOCs was proposed and evolved so far, MOOCs has become the hottest word in education today. Four well-known domestic universities, including Tsinghua University, Peking University, Fudan University and Shanghai Jiaotong University, joined the tide of MOOCs in 2013. All colleges and universities in Shanxi Province cannot sit still. We should actively explore the application of MOOCs teaching ideas and methods to constantly improve the effectiveness of teacher teaching and then the overall ability of students would be enhanced.

Fund Project: Shanxi Province, education and scientific planning project, "Shanxi Province, colleges and universities to carry out MOOCs conditions and path"; Shanxi University of Finance and Economics teaching reform research project, "local colleges and universities to carry out the way to study."

\author{
SUN Guoqiang \\ Research Department \\ Shanxi University of Finance and Economics, SXUFE \\ Taiyuan, China \\ gqsun@163.com \\ ZHAO Wen \\ School of Management Science and Engineering \\ Shanxi University of Finance and Economics, SXUFE \\ Taiyuan, China \\ tyqyxlj1@sina.cn
}

\section{LITERATURE REVIEW}

The term MOOCs was proposed by Canadian scholar Bryan Alexander and Dave Cormier in 2008. Zutshi et al. searched 21 blogs from 20 different MOOCs learners through Google blogs and studied how students learned and felt in MOOCs learning by content analyzing[1]. They found that students' experience with MOOCs was related to students' abilities. Students who experience relatively positively are usually those who are able to complete the MOOCs course. While relatively negative experience came from those who completed MOOCs course task more difficult. Students' cognitive experiences have a significant impact on their performance in flipped classrooms[2]. Then the domestic scholars have done a lot of research on MOOCs. The MOOCs have many advantages, but it also faces many challenges in the process of development. We should actively develop domestic MOOCs courses, strengthen international cooperation, give full play to the advantages of traditional university teaching and MOOCs teaching, etc.[3]. Through the analysis of 231 online learning journals collected by Zhejiang University bilingual elective course "network and distance education", Li Yan and Zhang Muhua found: students have a rich emotional experience in the MOOCs' integration into the flip classroom learning; in the interaction with others, students prefer the face-to-face communication rather than online communication; teacher's encouragement can also improve the student's experience in flipped classroom[4].

Liu Yi pointed out that "MOOCs" has the application limitations in the language, information technology, interaction between teachers and students, etc., and proposed that we should strengthen the construction of school education informatization level and provide the basic guarantee conditions of "MOOCs"[5]. We should carry out the curriculum construction in the new era and promote the reform of the teaching mode. It is necessary to innovate the teaching support service system to maximize the benefits of "MOOCs" and make full use of it to promote the teaching. 
In summary, although MOOCs did not appear for a long time, their applications and researches have drawn the attention of scholars. A great deal of exploration and researches has been conducted on MOOCs in teaching mode, teaching effectiveness, flipped classroom and so on. And a good foundation for its application and development in higher education has been laid. At the same time, the researchers also realized that the MOOCs practice should be combined with the specific conditions. The complementary advantages of traditional teaching model are the key to play the advantages of MOOCs, and then improve the educational model to a new height level. Based on the present situation of MOOCs, this paper studies the conditions to develop MOOCs in Shanxi universities and the path of combining MOOCs with traditional teaching methods, that is, the way for MOOCs to land in colleges and universities in Shanxi.

\section{CONDITIONS ANALYSIS}

MOOCs is different from traditional classroom teaching. Its application requires specific supportive conditions. Therefore, analysis found that there are four guarantees for Shanxi universities to carry out and apply MOOCs to teaching practice, which are Government support, school system, teachers, and teaching resources respectively.

\section{A. Financial Support from Government}

In our country, most universities rely on government investment institutions. Shanxi government attaches great importance to the development of Shanxi higher education.

\section{B. System Guarantee of Shanxi Universities}

While paying attention to the evaluation of teachers' hard targets, the colleges and universities also provide their teachers with a more humane environment and ample time. Then they have the flexibility to implement and innovate teaching methods according to the courses.

\section{Rich Teacher Resources}

Most teachers in Shanxi province have master's and doctoral degrees with high professional skills. They also have a group of teachers and teaching assistant teams who are willing and able to engage in MOOCs teaching.

\section{Relatively Adequate Teaching Resources}

In Shanxi colleges and universities, such as Shanxi University, Taiyuan University of Technology, Shanxi Finance University, and North Central University and so on, each classroom is equipped with computers, projectors and other hardware facilities. And the vast majority of college students in Shanxi are equipped with computers. These hardware facilities provide the basic guarantee for the development of MOOCs. In addition, WiFi has basically achieved full coverage of the campus, and student residences are also equipped with wireless WiFi networks, , which enable them to access MOOCs for learning anytime, anywhere, on campus.

From the above conditions, Shanxi colleges and universities have the basic conditions for carrying out MOOCs. However, there is still a long way to go to colleges and universities in developed areas. Therefore, careful planning and tailor-made path design are needed to increase the success rate of MOOCs landing.

\section{PATH RESEARCH}

MOOCs has brought unprecedented challenges to traditional higher education. The wave of China's higher education reform is overwhelming. Therefore, Shanxi high schools should also give full play to the advantages of traditional teaching and MOOCs teaching. Take an innovative approach such as combining the two organically to promote the teaching mode as "online + offline". That will promote education reform in Shanxi. The path to implement MOOCs in Shanxi universities is shown in Fig. 1.

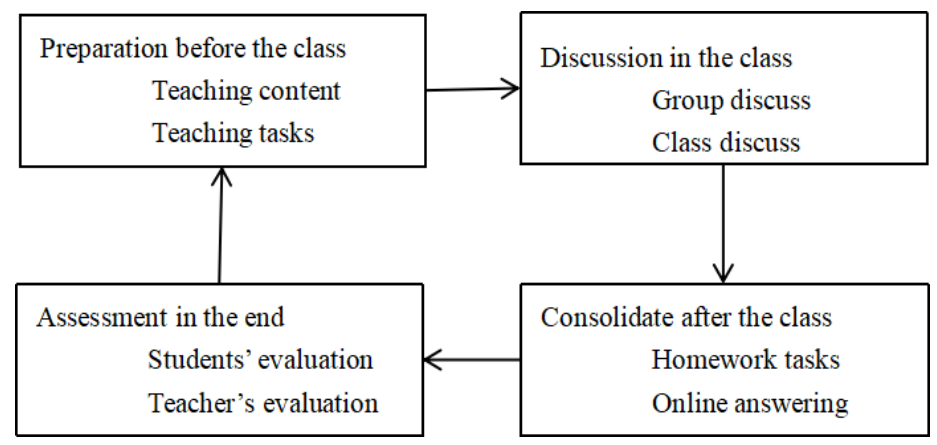

Fig. 1. The path to implement MOOCs in Shanxi universities

The development of MOOCs in colleges and universities in Shanxi specifically includes four stages.

\section{A. Pre-class Preparation Stage}

Before class, the teacher should clarify the teaching content and teaching tasks. Then according to the teaching content, the resources on the MOOCs are classified and then processed, and provided to the students. However, those are just for reference. In order to give full play to students' subjective initiative, in addition to learning resources provided by teachers, students should also find relevant resources for further study. That is good for further expand the breadth and depth of knowledge and lays the foundation for the next phase of class discussion. The emergence of MOOCs provides students with a great right choice. Students can study anytime and anywhere to improve their learning efficiency.

\section{B. Class Discussion Stage}

The class discussion stage is divided into two parts: group discussion and class discussion. First of all, the teacher explained the core knowledge of the course. Then, each member posed his own question in his own group, all group discussed it. The group discussion is followed by a class discussion. The issues discussed were the ones that failed to be discussed in the group. At this moment the teacher is involved again. As the general coordinator, the teacher organizes class discussions. And they explain their own failures or controversial issues in class discussions. Finally, the teacher summed up the discussion and arranged for homework. The "flip classroom" teaching methods makes the traditional 
teacher-oriented classroom a student-oriented classroom. The role of teachers has undergone fundamental changes.

\section{After-school Consolidation Stage}

The students submit the homework assignments of the class to the MOOCs platform and share them. The students and teachers then discuss the problems in homework. After homework was submitted to the MOOCs platform, teachers and students further exchange ideas about the homework. It helps students understand and grasp the learned knowledge.

\section{Final Assessment Stage}

The final examination stage is divided into student evaluation and teacher evaluation. On the MOOCs platform, after the discussion, the student scored for other students' homework. Then, the teacher gives the grade of every student. Student evaluation and teacher evaluation respectively accounted for $50 \%$ of the course grade. After the whole course is finished, the result of each course is converted into the final grade of the course by using a certain mathematical method. In this way, students can avoid the disadvantages of focusing on the final test scores and neglecting the grades of each course.

\section{PATH RESEARCH}

MOOCs is an educational innovation adapted to the development of the Internet era. It will have a profound impact on the teaching of traditional colleges and universities. Compared to the universities in the eastern coast, the educational resources of Shanxi University are obviously insufficient and the education and teaching conditions are at a disadvantage. Through the MOOCs, the open resources could enhance the quality of local education and teaching. That will promote Shanxi universities develop synchronously with the most famous universities in the world.

By analyzing the status quo of Shanxi colleges and universities, this paper finds that Shanxi Province has provided MOOCs conditions including the government's financial support, institutional security in colleges and universities and teaching resources. Then, from the perspective of giving play to the advantages of traditional teaching and MOOCs teaching in Shanxi colleges, an $\mathrm{O} 2 \mathrm{O}$ innovation teaching mode is put forward and a MOOCs implementation path is proposed. The path includes the preparatory phase of the class, the class discussion stage, after-school review stage. It can solve the current MOOCs' landing in Shanxi colleges and universities.

\section{REFERENCES}

[1] Zutshi, S., O'Hare, S., \& Rodafinos, A. Experiences in MOOCs: The Perspective of Students[J]. American Journal of Distance Education, 2013, 27(4): 218-227.

[2] Kim, M. K., Kim, S. M., \& Khera, O. et al. The Experience of Three Flipped Classrooms in an Urban University: An Exploration of Design Principles [J]. The Internet and Higher Education, 2014, (22): 37-50.

[3] Jiao Wei .Under the background of China's higher education teaching model reform and innovation [J] .Investment Education Research, 2014,04: 83-86 +93.

[4] Li Yan, Zhang Muhua. An Empirical Study on College Students' Classroom Experience-Based on 231 online learning log analysis [J]. Modern distance education research, 2015,05: 73-84 +93.

[5] Liu Yi. Thinking and practice of the construction of the MOOCs in local colleges and Universities [J]. Journal of Yangtze University (Social Science Edition), 2016,10: 80-83. 